\title{
Effects of Helicobacter pylori and Heat Shock Protein 70 on the Proliferation of Human Gastric Epithelial Cells
}

\author{
Liping Tao, ${ }^{1}$ Hai Zou, ${ }^{2}$ and Zhimin Huang ${ }^{1}$ \\ ${ }^{1}$ Department of Gastroenterology of the first Affiliated Hospital of Wenzhou Medical University, Wenzhou, Zhejiang 325000, China \\ ${ }^{2}$ Department of Hepatology, The Sixth Affiliated Hospital of Wenzhou Medical University, Lishui, Zhejiang 323000, China \\ Correspondence should be addressed to Hai Zou; haire1993@163.com
}

Received 18 April 2014; Accepted 1 July 2014; Published 5 August 2014

Academic Editor: Spiros D. Ladas

Copyright (c) 2014 Liping Tao et al. This is an open access article distributed under the Creative Commons Attribution License, which permits unrestricted use, distribution, and reproduction in any medium, provided the original work is properly cited.

\begin{abstract}
Infection of Helicobacter pylori (H. pylori) changed the proliferation of gastric epithelial cells and decreased the expression of heat shock protein 70 (HSP70). However, the effects of H. pylori on the proliferation of gastric epithelial cells and the roles of HSP70 during the progress need further investigation. Objective. To investigate the effects of Helicobacter pylori (H. pylori) and heat shock protein 70 (HSP70) on the proliferation of human gastric epithelial cells. Methods. H. pylori and a human gastric epithelial cell line (AGS) were cocultured. The proliferation of AGS cells was quantitated by an MTT assay, and the expression of HSP70 in AGS cells was detected by Western blotting. HSP70 expression in AGS cells was silenced by small interfering RNA (siRNA) to investigate the role of HSP70. The siRNA-treated AGS cells were cocultured with $H$. pylori and cell proliferation was measured by an MTT assay. Results. The proliferation of AGS cells was accelerated by coculturing with $H$. pylori for 4 and $8 \mathrm{~h}$, but was suppressed at 24 and $48 \mathrm{~h}$. HSP70 expression was decreased in AGS cells infected by $H$. pylori for $48 \mathrm{~h}$. The proliferation in HSP70-silenced AGS cells was inhibited after coculturing with $H$. pylori for 24 and $48 \mathrm{~h}$ compared with the control group. Conclusions. Coculture of $H$. pylori altered the proliferation of gastric epithelial cells and decreased HSP70 expression. HSP70 knockdown supplemented the inhibitory effect of $H$. pylori on proliferation of epithelial cells. These results indicate that the effects of $H$. pylori on the proliferation of gastric epithelial cells at least partially depend on the decreased expression of HSP70 induced by the bacterium.
\end{abstract}

\section{Introduction}

Gastric colonization by $H$. pylori occurs in more than half of all humans [1,2], especially in Asia. H. pylori is an important pathogen which is associated with peptic ulcers and chronic atrophic gastritis, as well as gastric mucosa-associated lymphoid tissue lymphoma. It has also been defined as a class I carcinogen by the International Agency for Research on Cancer (IARC) [3-6]. However, the pathogenic mechanism by which $H$. pylori is involved in these diseases remains unclear.

As the front line of defense against the noxious action of ingested food or contaminating pathogens such as $H$. pylori, gastric mucosal epithelial cells must maintain stable cytokinetics and the balance between proliferation and apoptosis. Otherwise, development of atrophic gastritis, intestinal metaplasia, and even gastric carcinoma can occur. Infection by $H$. pylori has been reported to be associated with either increased or reduced rates of gastric epithelial cell proliferation and apoptosis both in vivo and in vitro, depending on the study [7-14].

The heat-shock system is one of the most important systems for maintaining the viability of the cell and its resistance to the damaging effects of various physiological and environmental stressors [15]. As a member of the heatshock family, HSP70 is highly conserved, located in all cellular compartments including mitochondria, the endoplasmic reticulum, the cytosol, and the nucleus [16]. It is considered to play an important role in promoting proliferation and antiapoptosis [17-21]. Recent studies have indicated that specific downregulation of HSP70 in cells occurs in the presence of $H$. pylori $[12,22,23]$. However, there have been few studies on the role of HSP70 in the development of diseases of gastric epithelial cells infected by $\mathrm{H}$. pylori. These findings raise the possibility that HSP70 might be involved in pathogenesis of diseases caused by $H$. pylori, but the role 
of HSP70 during the infection process and the relationship between $H$. pylori, HSP70, and gastric epithelial cells need further investigation.

In the light of these findings, we presume that the effects of $H$. pylori on gastric epithelial cells depend on the alteration of HSP70 expression induced by the bacterium. Therefore, we performed several experiments to elucidate the effects of $H$. pylori on gastric epithelial cells and its relationship with HSP70.

\section{Materials and Methods}

2.1. H. pylori Culture. The H. pylori strain (ATCC 700392, $\mathrm{VacA}^{+}, \mathrm{CagA}^{+}$) was provided by Professor Ning Dai, Sir Run Run Shaw Hospital, Zhejiang University, and grown on Columbia solid agar medium (OXOID, England), supplemented with 5\% of fresh sheep's blood [24], and incubated in a microoxygen $\left(5 \% \mathrm{O}_{2}, 10 \% \mathrm{CO}_{2}\right.$, and $85 \% \mathrm{~N}_{2}$ ) environment at $37^{\circ} \mathrm{C}$ for $48 \mathrm{~h}$. The strain was confirmed during the culture. Before experimentation, bacteria were harvested and suspended in sterile PBS. The bacteria were counted using a spectrophotometer before administration to the cell culture, and suitable dilutions were prepared.

2.2. Cell Culture. The AGS human gastric epithelial cell line (CRL-1739, ATCC, USA) was provided by Zhejiang Key Laboratory of Traditional Chinese Medicine (TCM). Cells were grown in RPMI 1640 medium (Gibco, USA) which was supplemented with $10 \%$ fetal bovine serum, $100 \mu \mathrm{g} / \mathrm{mL}$ streptomycin, and $100 \mathrm{U}$ penicillin and incubated with $5 \%$ $\mathrm{CO}_{2}$ at $37^{\circ} \mathrm{C}$. Before the experiments, $5 \times 10^{3}$ of the AGS cells were seeded on 96-well plates and incubated overnight in RPMI 1640 medium, to which no antibiotics had been added. Cells were washed with sterile PBS before inoculation with the proper ratio of $H$. pylori or with RPMI 1640 alone. The cultures were incubated in a microoxygen $\left(5 \% \mathrm{O}_{2}, 10 \% \mathrm{CO}_{2}\right.$, and $85 \% \mathrm{~N}_{2}$ ) environment at $37^{\circ} \mathrm{C}$.

2.3. Effects of $H$. pylori on Proliferation of AGS Cells. AGS cells were cocultured with $H$. pylori at bacteria/cell ratios of $100: 1,200: 1$, and $500: 1$ for 4, 8, 24, and $48 \mathrm{~h}$. Control cells were incubated in medium alone. At the end of each incubation, the cells were collected by trypsinization, and cell proliferation was measured by an MTT assay: MTT ( $5 \mathrm{mg} / \mathrm{mL}$, Sigma) was added to each well, and the incubation was continued for $4 \mathrm{~h}$ at $37^{\circ} \mathrm{C}$. Finally, the culture medium was removed and dimethyl sulfoxide (DMSO) was added to each well. The absorbance was determined with an ELISA reader at $490 \mathrm{~nm}$ [25].

2.4. Effects of H. pylori on Expression of HSP70 in AGS Cells. Cells were incubated with $H$. pylori (bacteria/cell ratio $200: 1)$ or medium in absence of the bacteria for $48 \mathrm{~h}$. After washing twice with PBS, the cells were harvested. Whole-cell extracts were prepared as described elsewhere. For Western blots, $100 \mu \mathrm{g}$ of protein samples was boiled with Western blot sample buffer and loaded on SDS-PAGE gels. After electrophoresis and transfer of the samples, the

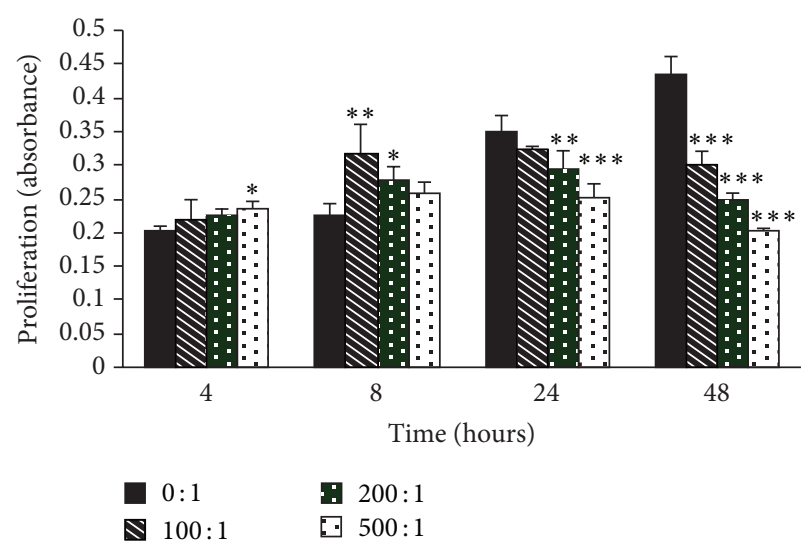

Figure 1: The effects of $H$. pylori on the proliferation of gastric epithelial cells. AGS cells were grown alone or with $H$. pylori (bacterium/cell ratio from $100: 1$ to $500: 1$ ) for 4, 8, 24, and $48 \mathrm{~h}$. The proliferation of AGS cells was measured by an MTT assay. The results are expressed as absorbance at $490 \mathrm{~nm}$. The data are shown as means $\pm \mathrm{SD}\left({ }^{*} P<0.05,{ }^{* *} P<0.01\right.$, and ${ }^{* * *} P<0.001$ when compared with different groups, resp.).

PVDF membrane (Millipore, Bedford, MA) was incubated with blocking buffer (5\% nonfat dried milk in PBS) for $30 \mathrm{~min}$ at room temperature. This was followed by overnight exposure to primary antibody for HSP70 (diluted 1:4000) or $\beta$-actin (diluted 1:1000) (Santa Cruz, USA) and a 1-hour exposure to secondary antibody (diluted $1: 5000$ ) in blocking buffer. After each antibody probing, the membrane was washed three times for 10 minutes in TBST buffer. An ECL chemiluminescence reagent (Kibbutz Beit Haemek, Israel) was used to show the positive bands on the membrane [11].

\subsection{Effects of H. pylori on Proliferation of HSP70-Silenced} AGS Line. To clarify the effects of HSP70, we studied an HSP70-silenced AGS cell line which had been constructed previously in our laboratory. AGS cells which had been stably transfected with siRNAs of the control (siControl) or HSP70 (siHSP70) had a knockdown of HSP70 expression confirmed by RT-PCR and Western blot analysis (data not shown). In this study, siHSP70-transfected AGS cells and siControl-transfected AGS cells were cocultured with $H$. pylori (bacteria : epithelial cell ratio $200: 1$ ) for 4, 8, 24, 48, and $72 \mathrm{~h}$. The siControl-transfected AGS cells were used as a control group. Cell proliferation was measured by an MTT assay as described above.

2.6. Statistical Analysis. Data are shown as means \pm SD. The significance of the differences between the control group and the experimental group was evaluated by rank sum tests (Figure 1) and Student's $t$-tests (Figure 3).

\section{Results}

3.1. H. pylori Altered Proliferation of AGS Cells. The MTT assay showed that $H$. pylori altered cell proliferation in the AGS line, and the effect was dependent on the concentration 


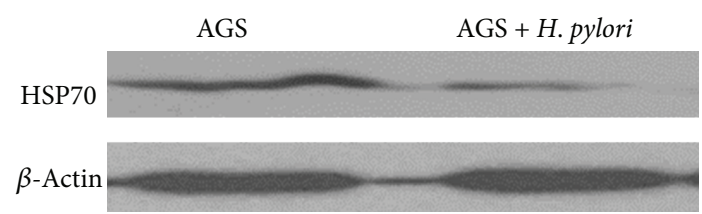

FIGURE 2: $H$. pylori effects on HSP70 expression in AGS cells. AGS cells were incubated with $H$. pylori (bacteria/cell ratio $200: 1$ ) or medium in absence of the bacterium for $48 \mathrm{~h}$. The expression of HSP70 was measured by Western blotting. Anti- $\beta$-actin antibody was used to measure $\beta$-actin as a protein-loading control.

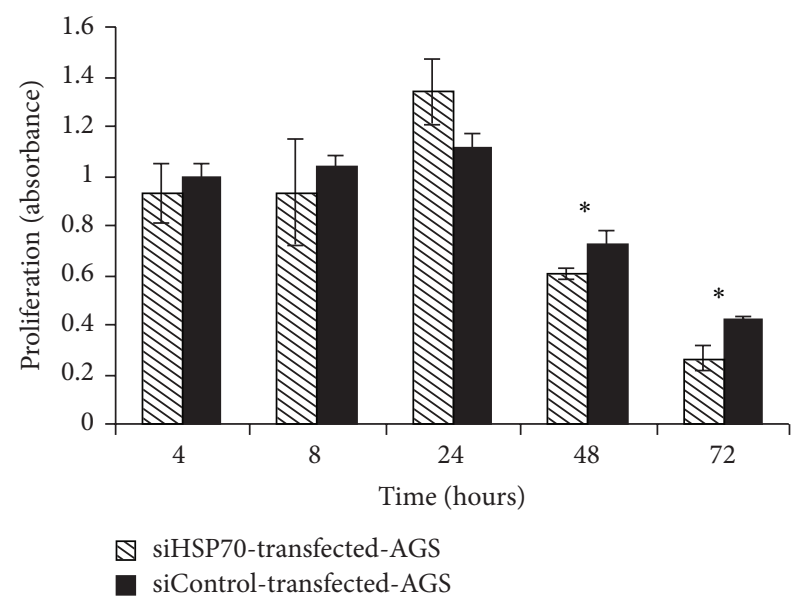

FIgURE 3: Proliferation of HSP70-silenced AGS line exposed to $H$. pylori. The HSP70-silenced AGS line (siHSP70-stably transfectedAGS cells) and control cells (siControl-stably transfected-AGS cells) were cocultured with $H$. pylori (bacteria : epithelial cell ratio $200: 1$ ) for the indicated times. Then, cell proliferation was detected by an MTT assay as described above. The results were expressed as absorbance. The data was shown as means $\pm \mathrm{SD}\left({ }^{*} P<0.05\right.$, when compared with the control group).

of $H$. pylori as well as the duration of infection. After incubation for 4 and $8 \mathrm{~h}$, cell proliferation in all of the study groups which were cocultured with $H$. pylori was significantly higher than that in control group, especially in the groups with a bacterium/cell ratio of $500: 1$ at $4 \mathrm{~h}(P<0.05), 200: 1$ at $8 \mathrm{~h}(P<0.05)$, and $100: 1$ at $8 \mathrm{~h}(P<0.01)$. This indicated that $H$. pylori effects on cell proliferation in the AGS line occurred early after infection. However, after exposure for $24 \mathrm{~h}$, cell proliferation in the study groups was inhibited, especially in the groups with a bacterium/cell ratio of $200: 1$ $(P<0.01)$ and $500: 1(P<0.001)$, and more obviously in all of the study groups $(P<0.001)$. The inhibitory effects were concentration-dependent (Figure 1).

\subsection{H. pylori Decreased HSP70 Expression in AGS Cells.} To investigate the molecular mechanism responsible for $H$. pylori-induced alteration of proliferation in AGS cells, HSP70 expression was measured in AGS cells infected by $H$. pylori. Addition of $H$. pylori to AGS cells significantly decreased HSP70 expression compared with cells which were grown in media with serum alone (Figure 2).
3.3. Proliferation of HSP70-Silenced AGS Line Exposed to H. pylori. The HSP70-silenced AGS line (siHSP70-stably transfected-AGS cells) and control cells (siControl-stably transfected-AGS cells) were incubated with $H$. pylori for $72 \mathrm{~h}$. The MTT assay showed that, after coculturing for 48 and $72 \mathrm{~h}$, proliferation in siHSP70-stale transfected-AGS cells was significantly lower than that in control group $(P<0.05)$ (Figure 3).

\section{Discussion}

Maintaining the balance between proliferation and apoptosis is important for gastric epithelial cells to maintain their normal function and prevent gastric diseases. Our data showed that $H$. pylori obviously changed the proliferation of gastric epithelial cells by transiently promoting proliferation at early time points and then inhibiting proliferation at later time points. This transition of the effects induced by $H$. pylori on the proliferation of gastric epithelial cells differs from the results of other researchers. Most of those authors showed that $H$. pylori inhibited proliferation in gastric epithelial cells $[12,13,26-29]$, while others showed that $H$. pylori stimulated proliferation in gastric epithelial cells $[8,10,11$, 14, 30-32]. In addition, a few studies showed that the effect of $H$. pylori on cell proliferation was related to bacterial concentration. Xu et al. showed that low concentrations of $H$. pylori stimulated cell proliferation, while high concentrations inhibited proliferation and promoted apoptosis [25]. Ismail et al. found that low doses of outer membrane vesicles from $H$. pylori increased proliferation of AGS gastric epithelial cells, while, at higher doses, cell growth was arrested [33].

Our data showed that the inhibition on cell proliferation was not only related to infection time, but also related to the concentration of $H$. pylori. The variation of the results among this research may be due to the diversity of experiment design and methods, such as live $H$. pylori, culture filtrates, or $H$. pylori extracts.

In our study, H. pylori promoted proliferation of AGS cells at an early time which may be a stress reaction of cells to the inhibitor. Then, the effect was changed to suppress cell proliferation at a later time of $H$. pylori infection. This transition might be related to the time needed for the synthesis and secretion of virulence factors and related proteins of $H$. pylori.

HSP70 proteins act as molecular chaperones in the cell and play an important role in regulating cellular growth, promoting proliferation and antiapoptosis [34, 35]. In tumor cell lines, the increase in HSP70 expression has been shown to stimulate cell proliferation [36], while specific inhibition of HSP70 expression suppressed cell proliferation and increased apoptosis [37]. Our data showed that live H. pylori decreased HSP70 expression in gastric epithelial cells. This is consistent with a recent report which showed that HSP70 gene expression was specifically downregulated in gastric epithelium exposed to live $H$. pylori [12]. Konturek et al., using mice as their model for in vivo stomach infection with live H. pylori, had similar results [22]. These findings implied that HSP70 might participate in the pathogenic process caused by live 
H. pylori. In order to further understand the role of HSP70 in the development of diseases of gastric epithelial cells infected by $H$. pylori, we knocked down the expression of HSP70 in gastric epithelial cells by siRNA. Our data showed that HSP70 knockdown reinforced the inhibition effect of $H$. pylori on cell proliferation in gastric epithelial cells. This implies that the effect of $H$. pylori on the proliferation of gastric epithelial cells at least partially depends on the reduced expression of HSP70 induced by the bacterium. However, more studies are needed to investigate the exact relationship and the molecular mechanism.

In summary, our study indicates that $H$. pylori can change the proliferation of gastric epithelial cells, and this process is probably mediated by HSP70. The data may provide additional information for the molecular mechanism by which $H$. pylori causes diseases, such as chronic gastritis and even cancer.

\section{Disclosure}

Hai Zou is a co-first author.

\section{Conflict of Interests}

The authors declare that they have no conflict of interests.

\section{References}

[1] H. M. Windsor and J. O'Rourke, "Bacteriology and taxonomy of Helicobacter pylori," Gastroenterology Clinics of North America, vol. 29, no. 3, pp. 633-648, 2000.

[2] S. Backert, E. Ziska, V. Brinkmann et al., "Translocation of the Helicobacter pylori CagA protein in gastric epithelial cells by a type IV secretion apparatus," Cellular Microbiology, vol. 2, no. 2, pp. 155-164, 2000.

[3] M. R. Amieva and E. M. El-Omar, "Host-bacterial interactions in Helicobacter pylori infection," Gastroenterology, vol. 134, no. 1, pp. 306-323, 2008.

[4] H. Vauhkonen, S. Heino, S. Myllykangas, P. M. Lindholm, S. Savola, and S. Knuutila, "Etiology of specific molecular alterations in human malignancies," Cytogenetic and Genome Research, vol. 118, no. 2-4, pp. 277-283, 2007.

[5] R. Lambert and P. Hainaut, "The multidisciplinary management of gastrointestinal cancer. Epidemiology of oesophagogastric cancer," Best Practice \& Research Clinical Gastroenterology, vol. 21, no. 6, pp. 921-945, 2007.

[6] "Schistosomes, liver flukes and Helicobacter pylori. IARC working group on the evaluation of carcinogenic risks to humans. Lyon, 7-14 June 1994," IARC Monographs on the Evaluation of Carcinogenic Risks to Humans, vol. 61, pp. 1-241, 1994.

[7] P. Bechi, M. Balzi, A. Becciolini et al., "Helicobacter pylori and cell proliferation of the gastric mucosa: possible implications for gastric carcinogenesis," The American Journal of Gastroenterology, vol. 91, no. 2, pp. 271-276, 1996.

[8] X. G. Fan, D. Kelleher, X. J. Fan, H. X. Xia, and P. W. N. Keeling, "Helicobacter pylori increases proliferation of gastric epithelial cells," Gut, vol. 38, no. 1, pp. 19-22, 1996.

[9] X. Fan, S. E. Crowe, S. Behar et al., "The effect of class II major histocompatibility complex expression on adherence of Helicobacter pylori and induction of apoptosis in gastric epithelial cells: a mechanism for T helper cell type 1-mediated damage," The Journal of Experimental Medicine, vol. 187, no. 10, pp. 1659-1669, 1998.

[10] A. De Luca, A. Baldi, P. Russo et al., "Coexpression of Helicobacter pylori's proteins CagA and HspB induces cell proliferation in AGS gastric epithelial cells, independently from the bacterial infection," Cancer Research, vol. 63, no. 19, pp. 6350-6356, 2003.

[11] Y. C. Chen, Y. Wang, J. Y. Li, W. R. Xu, and Y. L. Zhang, "H pylori stimulates proliferation of gastric cancer cells through activating mitogen-activated protein kinase cascade," World Journal of Gastroenterology, vol. 12, no. 37, pp. 5972-5977, 2006.

[12] P. Pierzchalski, A. Krawiec, A. Ptak-Belowska, A. Barańska, S. J. Konturek, and W. W. Pawlik, "The mechanism of heatshock protein 70 gene expression abolition in gastric epithelium caused by Helicobacter pylori infection," Helicobacter, vol. 11, no. 2, pp. 96-104, 2006.

[13] S. Z. Ding, M. F. Smith Jr., and J. B. Goldberg, "Helicobacter pylori and mitogen-activated protein kinases regulate the cell cycle, proliferation and apoptosis in gastric epithelial cells," Journal of Gastroenterology and Hepatology, vol. 23, no. 7, part 2, pp. e67-e78, 2008.

[14] Y. G. Yan, G. Zhao, J. P. Ma, S. R. Cai, and W. H. Zhan, "Effects of different Helicobacter pylori culture filtrates on growth of gastric epithelial cells," World Journal of Gastroenterology, vol. 14, no. 23, pp. 3745-3749, 2008.

[15] F. U. Hartl, "Molecular chaperones in cellular protein folding," Nature, vol. 381, no. 6583, pp. 571-580, 1996.

[16] B. Bukau and A. L. Horwich, "The Hsp70 and Hsp60 chaperone machines," Cell, vol. 92, no. 3, pp. 351-366, 1998.

[17] D. D. Mosser, A. W. Caron, L. Bourget, C. Denis-Larose, and B. Massie, "Role of the human heat shock protein hsp70 in protection against stress- induced apoptosis," Molecular and Cellular Biology, vol. 17, no. 9, pp. 5317-5327, 1997.

[18] M. Jäättelä, D. Wissing, K. Kokholm, T. Kallunki, and M. Egeblad, "Hsp7O exerts its anti-apoptotic function downstream of caspase-3-like proteases," The EMBO Journal, vol. 17, no. 21, pp. 6124-6134, 1998.

[19] E. M. Creagh, R. J. Carmody, and T. G. Cotter, "Heat shock protein 70 inhibits caspase-dependent and -independent apoptosis in Jurkat T cells," Experimental Cell Research, vol. 257, no. 1, pp. 58-66, 2000.

[20] A. E. Kabakov, K. R. Budagova, A. L. Bryantsev, and D. S. Latchman, "Heat shock protein 70 or heat shock protein 27 overexpressed in human endothelial cells during posthypoxic reoxygenation can protect from delayed apoptosis," Cell Stress Chaperones, vol. 8, no. 4, pp. 335-347, 2003.

[21] T. X. Xiang, Y. Li, Z. Jiang et al., "RNA interference-mediated silencing of the Hsp70 gene inhibits human gastric cancer cell growth and induces apoptosis in vitro and in vivo," Tumori, vol. 94, no. 4, pp. 539-550, 2008.

[22] J. W. Konturek, H. Fischer, P. C. Konturek et al., "Heat shock protein 70 (HSP70) in gastric adaptation to aspirin in Helicobacter pylori infection," Journal of Physiology and Pharmacology, vol. 52, no. 1, pp. 153-164, 2001.

[23] A. Targosz, P. Pierzchalski, A. Krawiec et al., "Helicobacter pylori inhibits expression of heat shock protein 70 (HSP70) in human epithelial cell line. Importance of Cag A protein," Journal of Physiology and Pharmacology, vol. 57, no. 2, pp. 265-278, 2006.

[24] C. Y. Hachem, J. E. Clarridge, D. G. Evans, and D. Y. Graham, "Comparison of agar based media for primary isolation of 
Helicobacter pylori," Journal of Clinical Pathology, vol. 48, no. 8, pp. 714-716, 1995.

[25] C. X. Xu, Y. M. Qi, W. B. Yang, F. Wang, J. D. Zhou, and S. R. Shen, "Effect of CagA+ helicobacter pylori strain on the expression of connexin 43 and cell proliferation in BGC-823 cells," Journal of Central South University, vol. 32, no. 2, pp. 288294, 2007.

[26] G. Chen, E. M. Sordillo, W. G. Ramey et al., "Apoptosis in gastric epithelial cells is induced by Helicobacter pylori and accompanied by increased expression of BAK," Biochemical and Biophysical Research Communications, vol. 239, no. 2, pp. 626632, 1997.

[27] H. H. Xia and N. J. Talley, "Apoptosis in gastric epithelium induced by Helicobacter pylori infection: implications in gastric carcinogenesis," American Journal of Gastroenterology, vol. 96, no. 1, pp. 16-26, 2001.

[28] H. Shirin, E. M. Sordillo, S. H. Oh et al., "Helicobacter priori inhibits the G1 to S transition in AGS gastric epithelial cells," Cancer Research, vol. 59, no. 10, pp. 2277-2281, 1999.

[29] R. M. Peek Jr., M. J. Blaser, D. J. Mays et al., "Helicobacter pylori strain-specific genotypes and modulation of the gastric epithelial cell cycle," Cancer Research, vol. 59, no. 24, pp. 61246131, 1999.

[30] R. M. Peek Jr., S. F. Moss, K. T. Tham et al., "Helicobacter pylori cagA + strains and dissociation of gastric epithelial cell proliferation from apoptosis," Journal of the National Cancer Institute, vol. 89, no. 12, pp. 863-868, 1997.

[31] V. Ricci, C. Ciacci, R. Zarrilli et al., "Effect of Helicobacter pylori on gastric epithelial cell migration and proliferation in vitro: role of VacA and CagA," Infection and Immunity, vol. 64, no. 7, pp. 2829-2833, 1996.

[32] F. Brenes, B. Ruiz, P. Correa et al., "Helicobacter pylori causes hyperproliferation of the gastric epithelium: pre- and posteradication indices of proliferating cell nuclear antigen," American Journal of Gastroenterology, vol. 88, no. 11, pp. 1870-1875, 1993.

[33] S. Ismail, M. B. Hampton, and J. I. Keenan, "Helicobacter pylori outer membrane vesicles modulate proliferation and interleukin- 8 production by gastric epithelial cells," Infection and Immunity, vol. 71, no. 10, pp. 5670-5675, 2003.

[34] P. C. Konturek, J. Kania, V. Kukharsky, S. Ocker, E. G. Hahn, and S. J. Konturek, "Influence of gastrin on the expression of cyclooxygenase-2, hepatocyte growth factor and apoptosisrelated proteins in gastric epithelial cells," Journal of Physiology and Pharmacology, vol. 54, no. 1, pp. 17-32, 2003.

[35] H. R. Wong, J. D. Finder, K. Wasserloos, and B. R. Pitt, "Expression of iNOS in cultured rat pulmonary artery smooth muscle cells is inhibited by the heat shock response," American Journal of Physiology, vol. 269, no. 6, part 1, pp. L843-L848, 1995.

[36] Ö. Canöz, O. Belenli, and T. E. Patiroǧlu, "General features of gastric carcinomas and comparison of HSP70 and NK cell immunoreactivity with prognostic factors," Pathology and Oncology Research, vol. 8, no. 4, pp. 262-269, 2002.

[37] Y. Q. Wei, X. Zhao, Y. Kariya, K. Teshigawara, and A. Uchida, "Inhibition of proliferation and induction of apoptosis by abrogation of heat-shock protein (HSP) 70 expression in tumor cells," Cancer Immunology Immunotherapy, vol. 40, no. 2, pp. 73-78, 1995. 


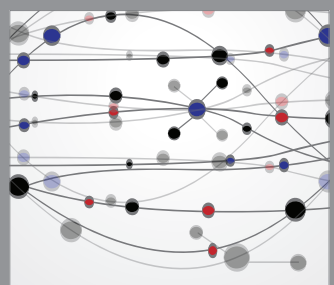

The Scientific World Journal
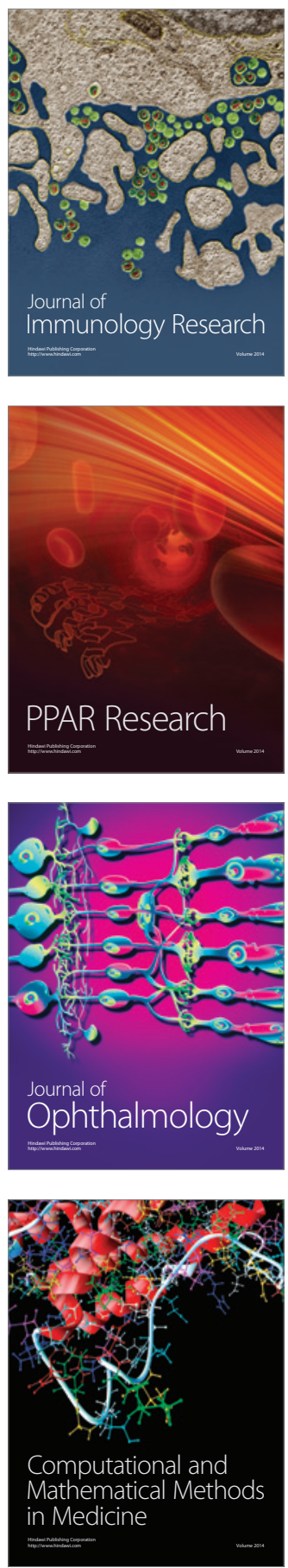

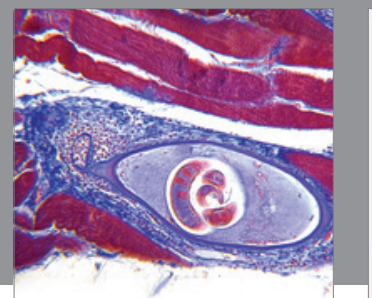

Gastroenterology

Research and Practice
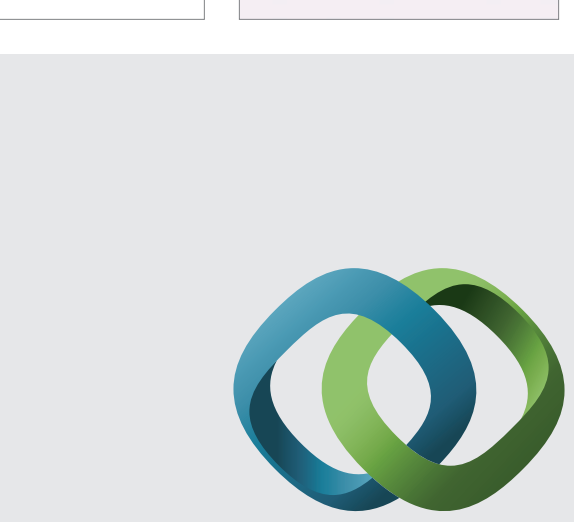

\section{Hindawi}

Submit your manuscripts at

http://www.hindawi.com
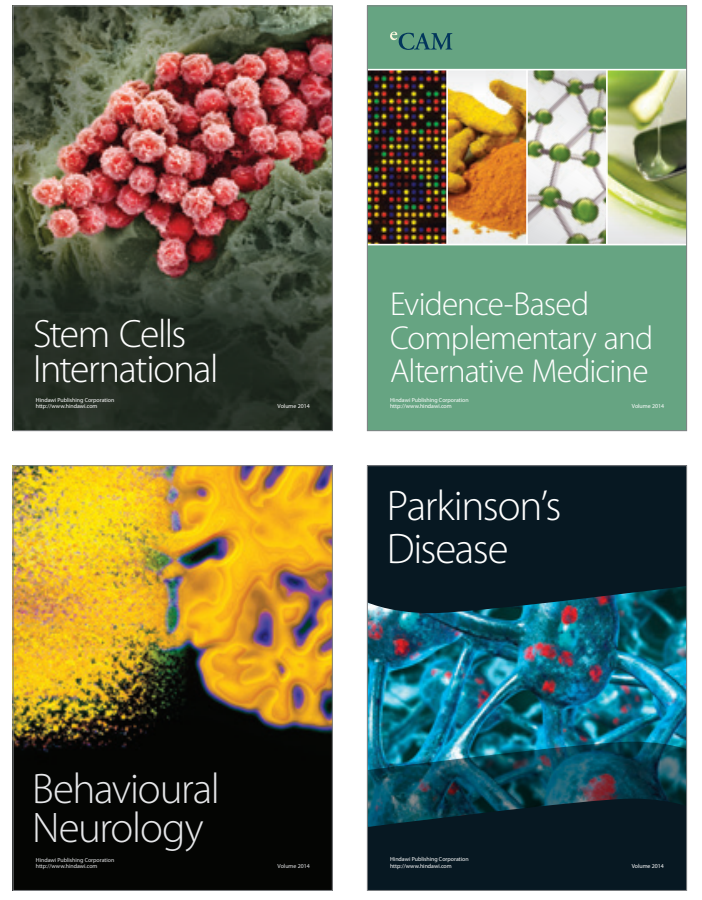
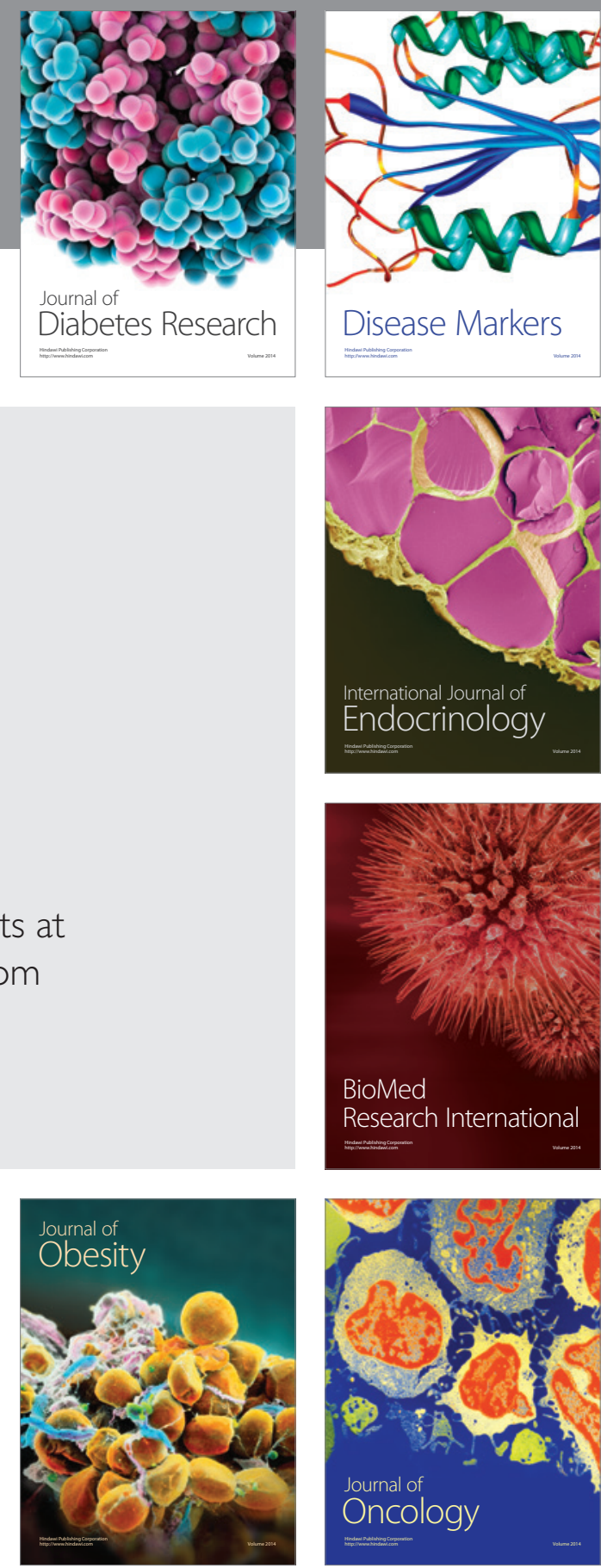

Disease Markers
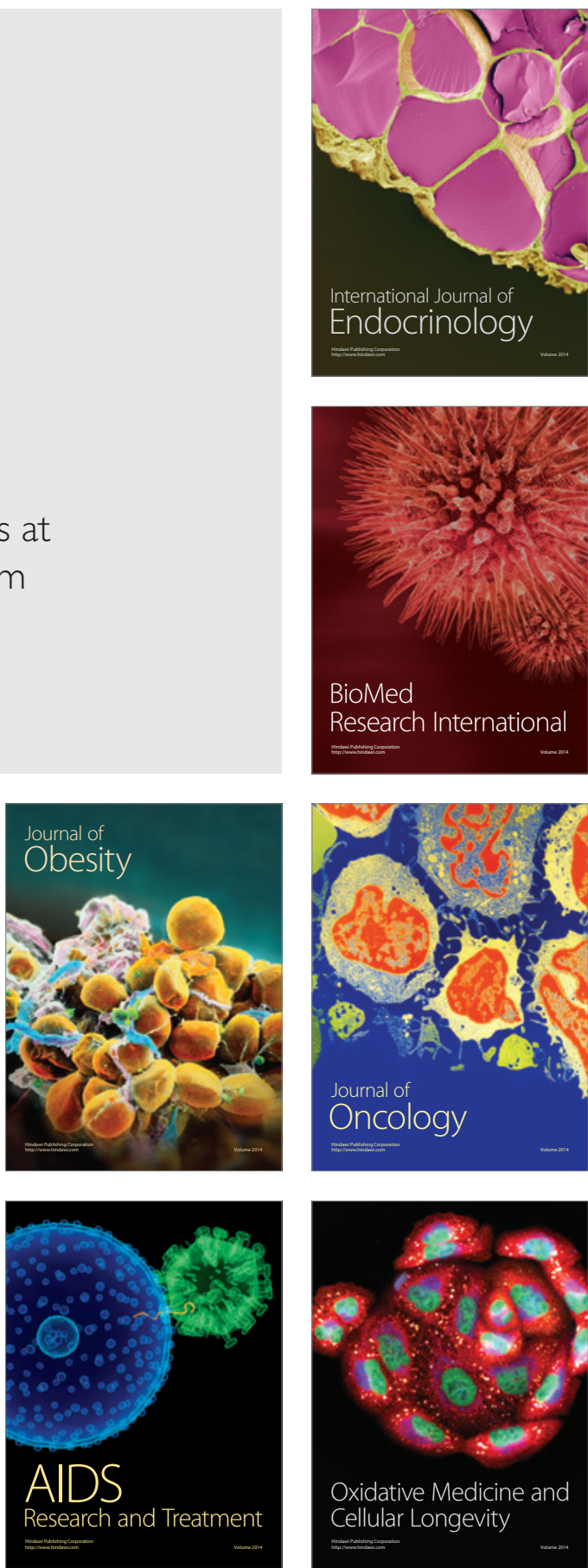